\title{
Massive rectal bleeding after prostate biopsy controlled by endoclipping in a patient using acetylsalicylic acid
}

\author{
Bora Özveren, MD; Levent Türkeri, $M D^{+}$ \\ *Acibadem University, Faculty of Medicine, Acibadem Kadikoy Hospital, Istanbul, Turkey; ${ }^{\dagger}$ Marmara University, Faculty of Medicine, Istanbul, Turkey
}

Cite as: Can Urol Assoc J 2013;7(5-6):e442-4. http://dx.doi.org/10.5489/cuaj.1390 Published online June 12, 2013.

\begin{abstract}
A case of severe rectal bleeding following transurethral ultrasound (TRUS)-guided prostate biopsy is reported. Rectal bleeding is considered a minor, transient complication of this standard diagnostic procedure that can usually be controlled successfully by conservative measures. In this case where the patient had been taking acetylsalicylic acid (ASA), massive bleeding required hospitalization and blood transfusions. Conservative treatment attempts were not succesful, and profuse rectal bleeding was eventually treated by colonoscopy and endoclipping of the bleeding vessel. Although generally regarded as a less significant complication, rectal bleeding may rarely be encountered as a life-threatening situation. Furthermore, conservative therapeutic approach to this minor complication may be ineffective in patients taking ASA. Early endoscopic intervention may be necessary to prevent blood transfusion and prolonged hospitalization in severe rectal bleeding after TRUS biopsy.
\end{abstract}

\section{Introduction}

Transrectal ultrasound (TRUS)-guided prostate biopsy is a standard procedure for the diagnosis of prostate cancer. It is generally a safe outpatient procedure with minimal rectal and genitourinary morbidity. Rectal bleeding is often seen in patients who undergo TRUS-guided prostate biopsy. Early and/or late bleeding is seen in up to about $25 \%$ of cases in large series. ${ }^{1}$ However, bleeding is usually mild and resolves spontaneously. Recent studies also revealed that continued use of acetylsalicylic acid (ASA) in men undergoing transrectal prostate biopsy did not increase the incidence of hemorhagic complications, but slightly prolonged the duration of self-limiting hematuria and rectal bleeding., ${ }^{2,3}$

We report a case of massive rectal bleeding following a 12-core biopsy in a patient using low-dose ASA. Several previous conservative measures of treatment failed to stop the rectal bleeding which caused hemodynamic instability. The patient was consequently treated by sigmoidoscopic endoclipping. We present the details of this case and review the literature.

\section{Case report}

A 61-year-old male with a medical history of hypertension had a 32-mL prostate associated with minimal lower urinary symptoms. Prostate-spesific antigen (PSA) was $4.05 \mathrm{ng} / \mathrm{mL}$ and small nodularity on the prostatic sulcus was palpated at rectal examination. The patient underwent a 12-core TRUS-guided prostate biopsy. He had his last 80-mg ASA the day before the biopsy. A slightly greater amount of rectal bleeding was noticed during the biopsy, but the procedure was otherwise uneventful. The patient had macroscopic hematuria and a bloody defecation during the short recovery time in the outpatient clinic following the biopsy. His vital signs were stable.

The following morning, he was admitted to the emergency clinic with complaints of continuing rectal bleeding and bloody stooling, tenesm, dizziness and 2 episodes of syncope. Abdominal examination was normal, but abundant fresh blood clots were found in the rectum (Fig. 1 ). Blood pressure was $147 / 55 \mathrm{mmHg}$, with a pulse rate $75 / \mathrm{min}$ and oxygen saturation of $99 \%$. He was hospitalized for intravenous fluid resuscitation and received a rectal gauzetamponade; he was also monitored with hourly blood counts. The patient's hemoglobin was $11.9 \mathrm{~g} / \mathrm{dL}$; it was $15 \mathrm{~g} / \mathrm{dL}$ before the TRUS-biopsy. He was transfused with 2 packs of eryhtrocyte suspension and a pack of fresh frozen plasma when the hematocrit level dropped to $8.5 \mathrm{~g} / \mathrm{dL}$. Profuse rectal bleeding continued despite tamponade and, following a brief response to the transfusions, the hemoglobin level decreased to $8.7 \mathrm{~g} /$ $\mathrm{dL}$ again. Another unit of packed red blood cells was given. He complained of lower abdominal tenderness. Abdominal computed tomography did not show any intraabdominal or pelvic hematoma. Eventually, the patient consulted a gastroenterologist, and flexible sigmoidoscopy was performed 


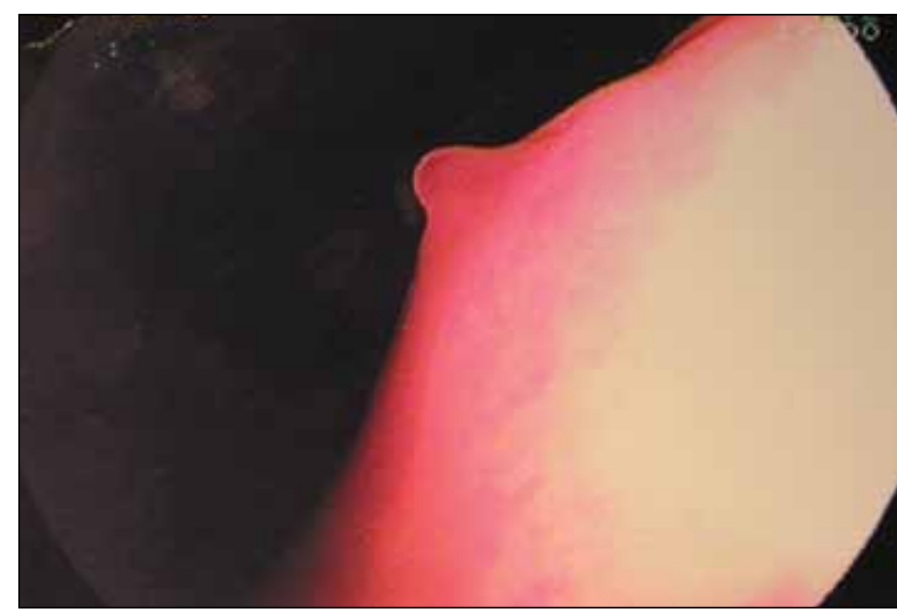

Fig. 1. The pulsatile bleeder on the rectal mucosa observed at endoscopic inspection.

without colonic preparation. Endoscopic examination revealed bloody stools in the initial $30 \mathrm{~cm}$. Following copious saline irrigation, a pulsatile bleeding was observed just a few centimeters proximal to the anal ring. The lesion, which was believed to be an arterial bleeder, was initially injected with $10 \mathrm{~mL}$ of 1:10000 epinephrine, but this attempt failed. Subsequently, 2 endoclips (QuickClip2, Olympus) were applied to mucosal surface of the spurting bleeder, which completely achieved hemostasis (Fig. 2).

The patient had no more bleeding episodes and his hemodynamics remained stable. He was started on oral therapy for anemia and discharged the next day.

\section{Discussion}

Minor complications are frequent (60\% to $79 \%$ ) after TRUSguided prostate biopsy, whereas major complications are rare $(0.4 \%$ to $4.3 \%)$. The need for hospitalization ranges from $0.4 \%$ to $3.4 \%$. Most hemorrhagic complications of prostate biopsy are insignificant and resolve without intervention. Persistent hematuria is the most common (70.8\%) complication. Rectal bleeding may occur just after the procedure and mild hematochesia may last 3 to 7 days in up to $25 \%$ of patients. ${ }^{4}$

The incidence of bleeding is usually correlated to the number of biopsy cores. In our clinic, a 12-core TRUS biopsy is routine to increase the diagnostic accuracy. The number of cores taken may even be higher due to the TRUS findings (e.g., prostate size, hypoechoic lesions). More biopsies per gland may be accompanied by patient discomfort and increased rate of complications. The prostate and surrounding rectal tissue consists of branches of the inferior vesical artery and the middle and inferior rectal arteries. The rectal vein plexus is also located in this region and can increase in size in case of hemorrhoids. Increased number of core biopsies performed is therefore potentially associated

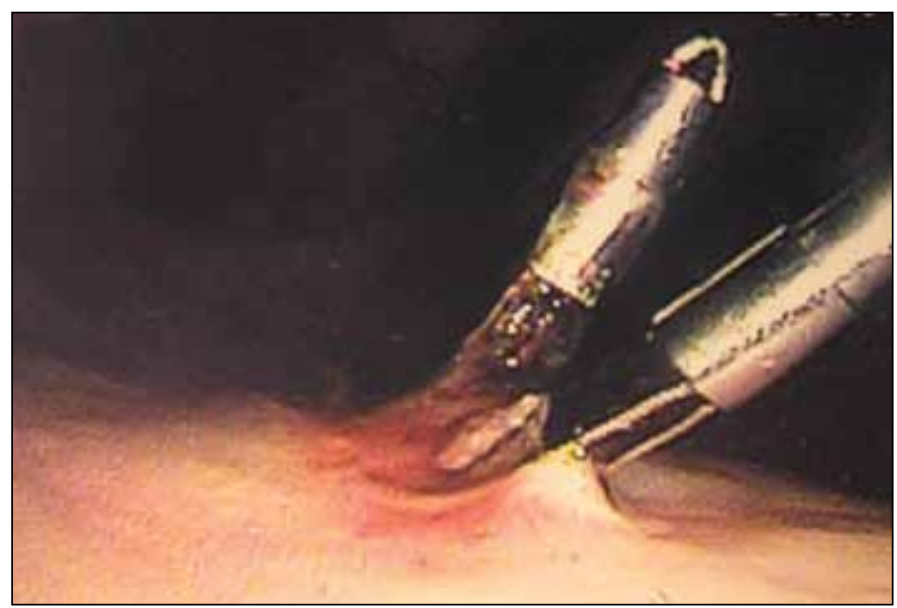

Fig. 2. Endoclips were applied to mucosal surface of the spurting bleeder, which completely achieved hemostasis.

with a higher risk of rectal bleeding. Sheikh and colleagues recommend transperineal removal of tissue rather than a transrectal biopsy in patients with severe hemorrhoids. ${ }^{5}$ Any abnormality that may increase the risk of bleeding should be routinely evaluated by history-taking and brief proctological examination before starting the procedure. In our case, the patient had no history of perianal pathology or bleeding diathesis. Pre-procedural examination revealed no abnormal findings related to rectal mucosa. A slightly increased oozing of blood was noticed during the procedure, however, this condition was not considered as an indication to halt the procedure. A rectal gauze tamponade was left for a short time at the end of the procedure as usual.

The technique of TRUS biopsy itself may affect the rate of complications. A study reported an increasing prevalence of rectal bleeding with 6-, 8- and 12-core biopsies at a rate of $17 \%, 26 \%$ and $27 \%$, respectively. The duration of bleeding was not significantly altered and subgroup analysis revealed no significant increase in prevalence and duration of rectal bleeding when the biopsies were performed with local anesthetic injection before the procedure. ${ }^{6}$

Our patient's procedure was executed in the usual fashion, where 12-core biopsy samples were taken following a periprostatic local anesthetic injection. Our case is unique due the severe, life-threatening rectal bleeding following the 12-core TRUS-guided prostate biopsy in a patient using ASA. Low-dose ASA usage is not regarded as a contraindication for TRUS-biopsy. A number of studies have demonstrated that there are no significant differences in the rate of serious bleeding complications following TRUS biopsy in patients taking anticoagulants and antiplatelets. ${ }^{2,3}$ However, some studies revealed that the incidence of minor bleedings may be increased or hematuria and rectal bleeding may be prolonged in patients using ASA., ${ }^{7,8}$ Raheem and colleagues recently emphasized that discontinuation of anticoagulants and antiplateletes is unnecessary in patients 
undergoing TRUS biopsy. In their study, the authors found no difference in the incidence of rectal bleeding in patients on anticoagulant/antiplatelet therapy and the control groups (40\% vs. $39 \%$, respectively). ${ }^{9}$ Since there is no evidence that low-dose ASA significantly increases the morbidity of the procedure, we do not routinely discontinue ASA before prostate biopsy. In fact this case was the only example in our series of 136 patients $(0.7 \%)$ with severe rectal bleeding requiring hospitalization.

Seven cases of massive rectal bleeding following needle biopsy of the prostate have been reported. ${ }^{10-16}$ Most of them resolved with conservative therapy. Severe rectal bleeding is usually managed conservatively by the urologist with rectal tamponade. When digital pressure and rectal packing fails, balloon tamponade with inflated Foley catheter was frequently used to control bleeding. Endoscopic intervention with injection of adrenaline and sclerosants, thermocoagulation and band ligation have been used successfully in some cases. Katsinelos and colleagues reported a case that was effectively treated with endoclipping, which is a common method used during endoscopy to treat gastrointestinal bleeding. ${ }^{16}$ Endoscopic hemoclip placement can easily be achieved and is effective in immediate control of bleeding. Two clips that were deployed at the surrounding mucosa of the arterial bleeder were sufficient for occlusion in our case. Endoclips dislodge spontaneously and are passed in the feces without any complications.

In our case, the patient was initially followed up conservatively and we expected a spontaneous cessation of the bleeding. However, this strategy in the setting of a severe bleeding necessitated a longer hospitalization time with several blood transfusions. On retrospect, this case would suggest that severe rectal bleeding following a 12-core TRUS biopsy in a patient taking ASA may not be amenable to a conservative therapeutic approach because the underlying mechanism was a direct arterial injury rather than a deficit in the coagulation mechanisms.

\section{Conclusion}

Prostate biopsy is the most important step in diagnosing prostate cancer, even though this procedure may be the source of grave complications. Apparently, risk factors for post-biopsy rectal bleeding have not yet been fully elucidated in specifically designed studies. However, physicians should be aware of the possibility of life-threatening rectal bleeding which may require early endoscopic intervention to prevent blood transfusion and prolonged hospitalization.
Competing interests: None declared.

This paper has been peer-reviewed.

\section{References}

1. Djavan B, Waldert M, Zlotta A, et al. Safety and morbidity of first and repeat transrectal ultrasound guided prostate needle biopsies: results of a prospective European prostate cancer detection study. J Urol 2001;166:856-60. http://dx.doi.org/10.1016/S0022-5347(05)65851-X

2. Giannarini $G$, Mogorovich A, Valent $F$, et al. Continuing or discontinuing low-dose aspirin before transrectal prostate biopsy: results of a prospective randomised trial. Urology 2007;70:501-5. http://dx.doi.org/10.1016/i.urology.2007.04.016

3. Kariotis I, Philippou P, Volanis D, et al. Safety of ultrasound-guided transrectal extended prostate biopsy in patients receiving low dose aspirin. Int Braz I Urol 2010;36:308-16.

4. Raaijmakers R, Kirkels WJ, Roobol MJ, et al. Complication rates and risk factors of 5802 transrectal ultrasound-guided sextant biopsies of the prostate within a population-based screening program. Urology 2002;60:826-30. http://dx.doi.org/10.1016/S0090-4295(02)01958-1

5. Sheikh M, Hussein AY, Kehinde E0, et al. Patients' tolerance and early complications of transrectal sonographically guided prostate biopsy: prospective study of 300 patients. J Clin Ultrasound 2005;33:452-6. http://dx.doi.org/10.1002/icu.20168

6. Ghani KR, Dundas D, Patel U. Bleeding after transrectal ultrasonography-guided prostate biopsy: a study of 7-day morbidity after a six-, eight- and 12-core biopsy protocol. BJU Int 2004;94:1014-20. http://dx.doi.org/10.1111/i.1464-410X.2004.05096.x

7. Carmignani L, Picozzi S, Bozzini $G$, et al. Transrectal ultrasound-guided prostate biopsies in patients taking aspirin for cardiovascular disease: A meta-analysis. Transfus Apher Sci 201 1;45:275-80. http://dx.doi.org/10.1016/..transci.2011.10.008

8. Halliwell $0 T$, Yadegafar $G$, Lane $C$, et al. Transrectal ultrasound-guided biopsy of the prostate: aspirin increases the incidence of minor bleeding complications. Clin Radiology 2008;63:557-61. Epub 2008 Jan 11. http://dx.doi.org/10.1016/i.crad.2007.09.014

9. Raheem OA, Casey RG, Galvin DJ, et al. Discontinuation of anticoagulant or antiplatelet therapy for transrectal ultrasound-guided prostate biopsies: a single-center experience. Korean J Urol 2012;53:234-9. Epub 2012 Apr 18. http://dx.doi.org/10.4111/kju.2012.53.4.234

10. Braun KP, May M, Helke C, et al. Endoscopic therapy of a massive rectal bleeding after prostate biopsy. Int Urol Nephrol 2007;39:1125-9. http://dx.doi.org/10.1007/s1 1255-007-9175-0

11. Strate LL, $0^{\prime}$ Leary MP, Carr-Locke DL. Endoscopic treatment of massive rectal bleeding following prostate needle biopsy. Endoscopy 2001;33:981-4. http://dx.doi.org/10.1055/s-2001-17920

12. Gonen $M$, Resim $S$. Simplified treatment of massive rectal bleeding following prostate needle biopsy. Int J Urol 2004;11:570-2. http://dx.doi.org/10.1111/i.1442-2042.2004.00840.x

13. Daileh MI, Byre DJ. Severe bleeding following tranrectal tru-cut prostatic biopsy. Scand I Urol Nephrol 1996;3:153-4. http://dx.doi.org/10.3109/00365599609180908

14. Brullet E, Guevara MC, Campo R, et al. Massive rectal bleeding following transrectal ultrasound-guided prostate biopsy. Endoscopy 2000;32:792-5. http://dx.doi.org/10.1055/s-2000-7709

15. Kinney TP, Kozarek RA, Ylvisaker JT, et al. Endoscopic evaluation and treatment of rectal hemorrhage after prostate biopsy. Gastrointest Endosc 2001;53:117-9. http://dx.doi.org/10.1067/mge.2001.110919

16. Katsinelos $P$, Kountouras J, Dimitriadis $G$, et al. Endoclipping treatment of life-threatening rectal bleeding after prostate biopsy. World J Gastroenterol 2009;15:1130-3. http://dx.doi.org/10.3748/wig.15.1130

Correspondence: Dr. Bora Özveren, Acbadem University, Faculty of Medicine, Acbadem Kadikoy Hospital, Istanbul, Turkey; fax:+90 216 4284444; ozverenb@yahoo.com; bozveren@asg.com.tr 